\title{
The Creative Moment of Scientific Apprehension
}

Understanding the Consummation of Scientific Explanation through

Dewey and Peirce

\section{Mark Dietrich Tschaepe}

\section{(2) OpenEdition}

1 Journals

Electronic version

URL: http://journals.openedition.org/ejpap/578

DOI: 10.4000/ejpap.578

ISSN: 2036-4091

\section{Publisher}

Associazione Pragma

\section{Electronic reference}

Mark Dietrich Tschaepe, «The Creative Moment of Scientific Apprehension », European Journal of Pragmatism and American Philosophy [Online], V-1 | 2013, Online since 16 July 2013, connection on 23 April 2019. URL : http://journals.openedition.org/ejpap/578 ; DOI : 10.4000/ejpap.578

This text was automatically generated on 23 April 2019

\section{(9) $\Theta \Theta \Theta$}

Author retains copyright and grants the European Journal of Pragmatism and American Philosophy right of first publication with the work simultaneously licensed under a Creative Commons AttributionNonCommercial-NoDerivatives 4.0 International License. 


\title{
The Creative Moment of Scientific Apprehension
}

\author{
Understanding the Consummation of Scientific Explanation through \\ Dewey and Peirce
}

Mark Dietrich Tschaepe

"In the light of the doctrine of categories I should

say that an object, to be esthetically good, must have a multitude of parts so related to one another as to impart a positive simple immediate quality to

their totality..." (EP 2: 201)

"I suppose anyone who knows Mr. Einstein at present would say that he had quite as genuine and esthetic an experience from his mathematical calculations and their results that would mean nothing to us as he does from playing his violin."

(LW 13: 359)

1 When creativity is thought as a part of science, it is primarily considered as part of the innovative process - perhaps as the Eureka! moment of Archimedes - before some sort of scientific process takes over as strictly instrumental and removed from any sort of experience that could be deemed aesthetic. Even when the processes of constructing hypotheses and experiments are performed, these are rarely understood as creative in an artistic or aesthetic sense. Scientific experience and aesthetic experience seem to be antipodal. The former too often thought as merely consisting of mechanistic propositions, considered objective and rooted in those shared respects of experience that have been distilled of feeling for the sake of shared experimentation and reaching general conclusions. Aesthetics being considered as the realm of feeling - the qualitative realm of experience - that is regarded, at worst, as an individualistic hindrance to scientific thought, and, at best, as a problematic explanandum for which we need scientific explanans. 
2 Through his reconstructive philosophy, John Dewey facilitated re-connecting the scientific and aesthetic modes of experience. He realized that the two modes of experience were too often thought as mutually exclusive, pertaining only to objects that were considered as if they were of two distinct natural kinds. In his work, he warned against opposing science and aesthetic experience, whether through simply cleaving the two, or through valuing one above the other. He declared this opposition due to the "separation of the instrumental and the consummatory," and offered a corrective to this separation in his reconstruction of aesthetic experience as that which ties together seemingly isolated fields of experience (LW 1: 290). As he states in his essay, "Aesthetic Experience as Primary Phase":

the case of aesthetic experience with its cultivated development of the artistic variety out of what is natural and spontaneous in primary experience provides what, in all probability, is the simplest and most direct way in which to lay hold of what is fundamental in all the forms of experience that are traditionally (but fallaciously) regarded as so many different, separate, isolated, independent divisions of subject matter. (LW 16: 396)

3 In the following, I utilize Dewey's work that re-connects science with aesthetic experience in order to argue that scientific products are also aesthetic objects, i.e. objects that are part of our instrumental experience are also part of our aesthetic experience. As a part of aesthetic experience, scientific explanations are creative objects both within and outside of the proper domain of science. Specifically, I argue that scientific explanation, as Dewey conceives of it, is both instrumental and consummatory, and that when we experience scientific explanation in its consummation, this is what I deem a creative moment of scientific apprehension. This moment is one at which Charles S. Peirce hints in his Monist paper, "What Pragmatism Is" and is complemented by his categories of firstness and secondness (EP 2). It is a moment not restricted to scientists or aesthetes, being a moment of apprehension that occurs in everyday experience by non-specialists. By combining Dewey's conceptions of scientific explanation and aesthetic experience with Peirce's categories, an aspect of creativity regarding the products of scientific inquiry is acknowledged and understood as an important part of our reasoning process.

In order to argue that scientific explanation is both instrumental and consummatory, I first provide Dewey's instrumental conception of scientific explanation, which includes why science is so often considered as separated from aesthetic experience. Second, I present a general overview of Dewey's conception of aesthetic experience and the common division conceived between scientific experience and that of aesthetics. Third, I supply reasons to reconsider scientific experience as having an aesthetic dimension, especially with regard to scientific explanations and the creative moment of scientific apprehension. Finally, I discuss how recognition of this moment reveals an important aspect of creative reasoning that is to be understood as a part of our experience through what Peirce referred to as firstness and secondness. ${ }^{1}$

\section{Scientific Explanation as Instrumental}

5 John Dewey's work has proven to be a source of tension regarding science and aesthetics. Most Dewey scholars rightly object to any claims that Dewey is scientistic, and most agree that Dewey places importance upon both scientific inquiry and aesthetic inquiry throughout his work. One major point of controversy, as indicated by James Scott 
Johnston, has been "the proper role and scope of science in Dewey's concept of inquiry" (Johnston 2002: 1). Johnston has attempted to refute readings of Dewey as scientistic or positivistic (e.g. H.O. Mounce 1997; Leonard Waks 1998), in part, by remarking on the importance of aesthetic inquiry for Dewey, as well as the fact that the reach of aesthetic inquiry extends far beyond that of scientific inquiry. My purpose here is not to argue against Johnston or other Dewey scholars concerning the types of inquiry or the extension of aesthetic inquiry versus that of scientific inquiry; however, these scholars neglect and, at times, seemingly reject scientific products as part of aesthetic experience. In contrast, scientific explanations are not only scientific, but are also objects that one experiences aesthetically in everyday life. This is an important aspect of scientific explanation that becomes evident when we combine Dewey's work on science with that on aesthetics. It is important because Dewey's inclusion of the aesthetic regarding scientific products, such as explanations, provides a dimension of understanding the process and products of scientific inquiry that are too often neglected in philosophical analyses of science. This is especially true in the case of scientific explanation, wherein most accounts leave aside the actual experience of the moment of having or getting an explanation, treating scientific explanation as if it is something that simply remains within a separate 'realm' of scientific practice that is apart from our experience. Dewey's reconstruction of scientific experience provides an account of scientific explanation that aids in re-connecting the secondary experience of explanation with the primary experience of an explanation being had. His inclusion of the aesthetic dimension of experience is a fundamental part of this corrective reconstruction of scientific activity. Dewey's conception of aesthetics as applied to scientific practice indicates that scientific explanation is, in fact, consummated as an explanation because of its aesthetic dimension.

6 All of scientific practice, as is the case with any of our practices, is born from and is always part of experience. Dewey defined experience generally as "what men do and suffer, what they strive for, love, believe, endure, and also how men act and are acted upon, the ways in which they do and suffer, and desire and enjoy, see, believe, imagine" (LW 1: 8). Experience is the process of living, and it pertains to every type of interaction between the organism and its environment, including productive, discursive, and consummatory interactions (LW 12: 74). From and within experience, we engage in scientific processes when we are attempting to solve problems that pertain to the conditions of experience (LW 10: 211). Through the process of scientific inquiry, we transform our immediate experience, utilizing the sub-processes of analysis and synthesis. Analysis is the process of discrimination by which experience is pieced into particular objects, and synthesis is the process of identification wherein the objects of experience are re-unified as a whole (LW 8: 275). Experience is analyzed into data, which is the discernible material of our experience divided into distinct parts in our attempt to understand the conditions of experience, i.e. how or why a problem has or will or might possibly take place. This data is synthesized into ideas, which are the suggestions or possible solutions that are to be used to solve the questions addressing those conditions (LW 8: 197-198). This process signifies one of Dewey's most important distinctions within experience: that of primary and secondary experience. Primary experience is simply experiencing without analysis or synthesis. Most of our experience is merely primary, and most unproblematic primary experience goes unquestioned. Secondary experience is that which has been systematically analyzed and synthesized. It is that experience by 
which we attempt to understand primary experience. Analysis provides us with scientific products within secondary experience that are applied to primary experience in answering questions concerning experience. Scientific explanation is one type of scientific product created in this process. The explanations constructed from our secondary experience are tested against what we have questioned regarding primary experience (LW 1: 15-16). Thus, scientific explanations are the result of our inquiries into experience, and thereby become part of our experience, even when we are not engaged in scientific inquiry.

7 For Dewey, scientific explanation is a type of operation that is to be derived from a set of cases produced and analyzed (LW 12: 275). The explanation is applied to specific situations through the process of experimentation, testing whether or not the explanation actually solves the problem being addressed at the level of the conditions of experience. An explanation thereby provides a solution, or guide to a solution, for a problem or question regarding the conditions of experience. Scientific explanations are based upon a series of experiments, including the hypotheses that direct experiments, and through the conceptualization of the secondary experience of experimentation, scientific objects such as explanations are applied to primary experience.

The process of experimentation and explanation-generation is rife with creative processes, including abduction, the process of creating a probable solution to a problem, as Peirce conceived of it (Anderson 1987: 15). However, Peirce also hints at another creative process within the process of experimentation; one on which he never elaborates as a moment of creativity. This moment occurs between the sixth and seventh stage of experiment that he describes in his essay, "What Pragmatism Is" (EP 2: 339-40). Here he states that following the actual actions of the experiment, there "comes the subsequent reaction of the world upon the experimenter in a perception; and finally, his recognition of the teaching of the experiment" (EP 2: 340). Peirce's use of the term recognition indicates a re-cognizing, or what Dewey would call synthesis. However, Peirce's use of reaction and perception in the moment before recognition indicate awareness without secondary cognition; a felt quality had by the experimenter as the experiment comes to a close. There is an immediately grasped qualitative dimension of the experience of experimentation that accompanies the formulation of the solution to the question that drives the experiment, i.e. which consummates the experience.

9 As Dewey rightly noted, scientific processes typically ignore the immediately grasped qualitative dimension of experience (LW 5: 243). Peter Godfrey-Smith has remarked that Dewey's philosophy of science accounts for the neglect of the aesthetic by pointing to the instrumentalist practices of science. Most scientific practices merely involve "relations, potentialities, and interactions" (Godfrey-Smith 2002: S32). Dewey understood that "Scientific thought is, in its turn, a specialized form of art, with its own qualitative control," but that most people do not realize or acknowledge the qualitative and artistic nature of scientific practices (LW 5: 252). He reasoned that the failure to realize the immediate qualitative nature of formal scientific construction had two primary causes. The first was the common limited "habit of associating art and aesthetic appreciation with a few popularly recognized forms," while the second "is the fact that a student is so concerned with the mastery of symbolic or propositional forms that he fails to recognize and to repeat the creative operations involved in their construction" (LW 5: 242). This second reason I here expand to include anyone who is presented with scientific explanations. Science is primarily not included in the realms of art and aesthetic 
appreciation, instead being considered completely instrumental and actively antiaesthetic. In addition, we are typically not considered to be creating when being receptive to a scientific explanation. This mistakenly is thought of as a passive process. In fact, when we inquire and consider an explanation, this is an active process in which we actually engage. Similar to what Peirce stated concerning the process of experimentation, a reaction of the explanation upon the inquirer is a perception, and this is followed by the inquirer's recognition of what the explanation explains. For Peirce, "all of experience is 'a consciousness of reaction"' (Short 2007: 77) When a scientific explanation is presented, the inquirer both feels it and reacts to it, and this is not merely an instrumental activity, but can also be an aesthetic experience.

\section{Scientific Explanation Cleaved from Aesthetic Experience}

10 The aesthetic is a forgotten world in which the scientific resides. Godfrey-Smith has stated, "for Dewey science is the disinterested study of instrumentality in nature," and this is the case for most of the "decisions made within science" (S32). ${ }^{2}$ However, the scientific explanations that are constructed from within science are not only instrumental, but, as Dewey indicated, they are also able to be experienced as aesthetic. Neither of these experiences is somehow exclusive from the other, nor are they exclusive from the rest of our experience.

11 The aesthetic is that which has immediately enjoyed intrinsic meaning (LW 1: 271). In this manner, it is in direct contrast to the scientific processes of analysis and synthesis, which are the mediation of meaning. The latter entail discerning or 'figuring out' the meaning of a situation, and, in that respect, the situation is incomplete, i.e. unconsummated. In his work on Dewey's aesthetics, Van Meter Ames remarked, "The unaesthetic then is the slack, the loose, the confused, the lack of balance between doing and receiving" (Ames 1953: 146). This is the instrumental side of the scientific, which is a search for something apart from the experience being had. In fact, we often engage in scientific practices, including inquiring about and engaging with scientific explanations, in order to remove ourselves from our present experience; to effectively create a way out of our current, problematic, situation. An instrumental experience is open and incomplete. By its very nature as instrumental, it signifies seeking something to complete the experience.

According to Dewey, "every normally complete experience, every one that runs its course, is aesthetic in its consummatory phase..." (LW 16: 395). The aesthetic is then not isolated to what we often take to be artistic, but pertains to all complete experiences those which we can legitimately call an experience. As Richard Bernstein has stated: "Anything which is distinctly an experience, i.e. a situation which has a unity and wholeness of its own, has aesthetic quality" (Bernstein 1961: 8). In Experience and Nature, Dewey discusses the common conflation of the artistic and the aesthetic. The artistic pertains to those actions that manipulate a situation from an incomplete or unsatisfactory state to a state that is complete and satisfying. The aesthetic does not pertain to the actual artistic processes that complete the formerly incomplete or unsatisfying state, but rather, it pertains to "an enancement of the receptive appreciation and assimilation of objects" within the completed, satisfying state (LW 1: 267). Dewey 
continues that science is an art that aids in bringing about what he calls "the complete culmination of nature" and the union between the artistic and the aesthetic (LW 1: 268-9).

The qualities of an experience are immediate, and when the immediate grasp of qualities is of an experience that is complete and at its fullest, then that experience is aesthetic. Most often, aesthetic experience is mistakenly thought to be had only in the midst of what are considered 'art objects' or 'fine art.' Dewey fought tirelessly against this dualism imposed between 'fine art' and life. This included the artificial separation between what are considered to be 'the arts' and 'the sciences.' As Casey Haskins has indicated, Dewey rejected the Kantian argument that the products of art and science come from "two transcendentally distinct forms of mental activity," arguing instead that they emerge "from intelligence's more general impulse of striving for increasingly developed experience through a transformation of the world in which it finds itself" (Haskins 1992: 230). In the same regard that both are created from the same intelligent source, neither are they necessarily divided in how they are experienced. Just as the art product is often analyzed and synthesized, the scientific product is aesthetically experienced.

\section{Apprehending the Consummation of Scientific Explanation}

14 An aesthetic experience consists of the culmination of all of our emotion, awareness, inquiry, and interest in its immediacy. This is experienced often through films, musical pieces, sculptures, and paintings, i.e. objects of art or the 'fine arts.' As James Scott Johnston has indicated, Dewey placed a great emphasis on inquiry within the consummatory aesthetic experience. In his own investigation of the role of inquiry in the aesthetic experience, Johnston states that aesthetic reflection occurs "in the immediacy of the experience undergone, rather than in the realm of language" (Johnston 2002: 10). Johnston rightly notes that scientific method can become akin to an aesthetic object, although he restricts this to science only when "the act of discovery, of creation, is privileged" (Johnston 2002: 11). His exclusive categorization of science as aesthetic being conditional upon science only when it turns to discovery or creation stems from the separation that Johnston detects between the immediacy of creation, and the logical detachment of science as "the inquiry of statement," which is necessarily "removed from the immediacy of awareness necessary as a quality for any consummatory experience" (Johnston 2002: 11). Here I believe that Johnston is too restrictive in his account of science as it is presented by Dewey, overstressing the remark that "... there is an unbridgeable gap between science in the laboratory and the work of art" (LW 10: 126; quoted in Johnston 2002: 11). Johnston proclaims that:

\footnotetext{
An aesthetic object is generally able to evoke a far wider-ranging set of responses in a far wider-ranging set or group of people than a bald scientific statement. [...] Inquiry in an aesthetic experience functions as a more complete inquiry. It helps to fuse all of the ingredients necessary for a consummatory experience into one cohesive, immediate whole, whereas inquiry in a scientific experiment or logical understanding often contents itself to dwell in the explanatory realm alone. (Johnston 2002: 12)
}

Johnston undermines the potential aesthetic experience of scientific explanations without questioning what the aesthetic dimension of such a scientific product might be. Although he has acknowledged the aesthetic dimension of science when it is focused on 
discovery or creation, the consummatory phase of scientific explanation - the actual explanation itself - has been neglected prima facie. By reassessing Dewey's work concerning scientific products and aesthetic experience, we find that scientific explanations are actually objects that bring an important aesthetic dimension to our experience.

Qualitative experience includes scientific thinking, thereby including products of science, such as scientific explanations (LW 5: 261-2). Perhaps the most common qualitative experience had pertaining to science is that of felt difficulty, which is the immediate feeling that launches us into scientific inquiry. "The problem is had or experienced before it can be stated or set forth; but it is had as an immediate quality of the whole situation. The sense of something problematic, of something perplexing and to be resolved, marks the presence of something pervading all elements and considerations" (LW 5: 249). This is the qualitative experience at the inception of scientific inquiry, and just as there is a feeling of "something pervading all elements and considerations" as the problem, there is also the qualitative experience of the solution, i.e. qualitatively experiencing the explanation of the problem. As a solution, scientific explanation is often qualitatively experienced through what Mark Girod has deemed aesthetic understanding, a concept inspired by Dewey. Aesthetic understanding is defined as "a rich network of conceptual knowledge combined with a deep appreciation for the beauty and power of ideas that literally transform one's experiences and perceptions of the world" (Pugh and Girod 2007: 12). Utilizing this conception of aesthetic understanding as an epistemic network ingrained with an appreciation for what Peirce referred to as kalos - a generalized sense of harmony -, scientific explanations are those qualitative and epistemic objects that elegantly fit where our felt difficulty was (Hocutt 1962: 160). The explanation, as a totality, is felt aesthetically as what Peirce called "a positive immediate quality" (EP 2: 201). We do not only comprehend explanations, understanding them indirectly through a mediated process. There are also moments when we apprehend scientific explanations grasping their meaning directly - in our immediate engagement with them.

As a construction, scientific explanation is created over a period of time through a process of inquiry that is removed from the aesthetic. Again, most of scientific inquiry, following the initial felt difficulty, is mediated, but the artistry of scientific method sometimes ends in a completed, finished product: a scientific explanation that fully explains the problem that launched the inquiry. Dewey's conception of scientific explanation, combined with his conception of aesthetic experience, provide us with a way in which we can understand how our explanations sometimes simply feel as if they fit at the moment in which we receive them. The very process of apprehending the explanation consummates the experience, and it is an aesthetic experience in which we are fully absorbed. This is a rare moment in which science not only "states meaning," but fulfills the common role of art: it also expresses those meanings (LW 10: 90). The scientific explanation becomes both an expression and a statement. Although it is a generalized statement as a part of intellectual experience, it is also an expressive object in the moment in which it is aesthetically experienced. Our engagement with the explanation leads to our experiencing its expression and the achievement of kalos. A scientific explanation may strike us suddenly with what Dewey referred to as "tranquility of emotion and at the same time [...] excitement" (LW 13, 368). The explanation fixes the violent rupture brought to our experience through a felt difficulty. 
18 If the felt difficulty is the wound and ensuing infection that has "spread throughout the entire situation," then the explanation is the remedy that eradicates the infection (LW 8: 201). Our aesthetic experience of the explanation is that moment of consummation when the infected situation has been cleansed and cauterized, and we are presented with a clean bill of health. We feel the alleviation of our exigency. Our situation is not only remedied, but improved upon. Before analyzing and comprehending the scientific explanation, our aesthetic experience of it is that of a kind of panacea: the explanation feels as if it cures our problem without reflective details or grueling, meditative steps, but all at once, in one gesture. This is the creative moment of scientific apprehension, which is our individual experience of the scientific explanation consummated and felt at its fullest. In this moment we feel the full force of the scientific explanation as it answers our felt difficulty. It is creative because we experience the immediate making of a solution; we are swept in the process of making before mediation.

\section{The Feeling and Resistance of Creative Apprehension}

19 If, as Ignacio Götz states, "creativity is the process or activity of deliberately concretizing insight," then this moment of apprehension is that very moment of insight; it is creativity realized (Götz 1981: 300). Peirce provides a terminology here to understand how this moment contributes to the reasoning process. ${ }^{3}$ The quality of the explanation as it is experienced is what Peirce called a First or its firstness. In "A Guess at the Riddle," Peirce defines a First as that which is "present and immediate," "initiative, original, spontaneous, and free," as well as "vivid and conscious" (EP 1: 248). There is no way to describe adequately the felt experience of a First. In light of the initial felt quality of a scientific explanation as a First, Peirce's attempt at describing Adam on the first day of being conscious is apt: "first, present, immediate, fresh, new, initiative, original, spontaneous, free, vivid, conscious, and evanescent. Only, remember that every description of it must be false to it" (EP 1: 248). In addition to the firstness that constitutes scientific explanation in the creative moment of scientific apprehension, it is concomitantly constituted by what Peirce called Second, or secondness. This is the feeling of relation or reaction to the First, and the First is necessary for the Second to exist. Regarding our experience of scientific explanation in that moment before recognition, this reaction is one of engagement; the secondness of the situation indicates that we contribute to the experience of the explanation when we come "knocking up against it" (EP 1: 249). It is a moment of apprehension, in which an explanation is completed with regard to our own previously incomplete situation. We feel the explanation fitting our problem and solving it in its immediacy. The feeling of consummation at its fullest makes the creative moment of scientific apprehension an aesthetic experience, which brings our specific scientific inquiry to a close. What we are in the process of making during this experience is what will be the Third, but this only occurs after this creative moment of apprehension has passed. The Third will consist in the re-cognition of the experience and our attempt to represent the scientific explanation as a functional tool that solves our felt difficulty. This signifies the dissipation of aesthetically experiencing the scientific explanation through apprehension, returning to the instrumentality of comprehension.

We may find that we have had similar experiences with the same explanations as others, but the feeling of solution differs between individuals, and, as Peirce indicates, that feeling can never be described adequately. It is common for scientists to reminisce and 
venerate scientific theories and explanations. One of the reasons that scientists do this is because they have experienced creative moments of scientific apprehension, which returns them to what Dewey described as "a kind of innocence of the totality of experience" (LW 13: 364). There is something childlike in being swept away in an explanation as we aesthetically experience it. Some of the more common scientific theories and explanations experienced this way are: Darwin's theory of natural selection as an explanation for the variation between species; DNA as an explanation for genetic heredity; Quantum Theory as an explanation for why matter and energy behave in the ways that they do. The explanations are what we often describe as 'beautiful' or 'elegant,' thus ascribing an aesthetic or emotional quality to them. By re-evaluating the aesthetic experience of scientific explanations against the backdrop of Dewey's conceptions of aesthetics and science, combined with Peirce's categories, we can account for that creative moment of scientific apprehension in which a scientific explanation takes on the quality of kalos, or sense of general harmony. This is surely not our only aesthetic experience that is also scientific, but it is one that is important because it reinforces why we continue to be scientific and helps address the question of how scientific explanations inspire us creatively.

\section{BIBLIOGRAPHY}

AMEs V., (1953), “John Dewey as Aesthetician,” The Journal of Aesthetics and Art Criticism, 12 (2), 145-68.

ANDERSON D., (1987), Creativity and the Philosophy of C.S. Peirce, Dordrecht, Martinus Nijhoff Press. BERNSTEIN R., (1961), “John Dewey's Metaphysics of Experience,” The Journal of Philosophy, 58 (1), 5-14.

DEWEY J., The Middle Works of J. Dewey, 1899-1924, ed. by J.A. Boydston, Southern Illinois University Press, Carbondale and Edwardsville, 1976-1983.

DEWEY J., The Later Works of J. Dewey, 1925-1953, ed. by J.A. Boydston, Southern Illinois University Press, Carbondale and Edwardsville, 1981-1990.

GODFREY-SMITH P., (2002), "Dewey on Naturalism, Realism and Science," Philosophy of Science, 69 (S3), 525-35.

GÖTZ I., (1981), “On Defining Creativity,” The Journal of Aesthetics and Art Criticism, 39 (3), 297-301.

HASKINS C., (1992), “Dewey's Art as Experience: The Tension Between Aesthetics and Aestheticisms," Transactions of the Charles S. Peirce Society, 28 (2), 217-59.

HocutT M., (1962), “The Logical Foundations of Peirce's Aesthetics,” The Journal of Aesthetics and Art Criticism, 21 (2), 157-66.

JoHnSton J., (2002), “John Dewey and the Role of Scientific Method in Aesthetic Experience," Studies in Philosophy and Education, 21, 1-15.

MOUNCE H., (1997), The Two Pragmatisms: From Peirce to Rorty, London, Routledge. 
PEIRCE C., The Essential Peirce, Selected Philosophical Writings: Volume 1:1867-1893, ed. by N. Houser. and C. Kloesel, Bloomington, Indiana University Press, 1992.

PEIRCE C., The Essential Peirce, Selected Philosophical Writings: Volume 2: 1893-1913, ed. by N. Houser and C. Kloesel, Bloomington, Indiana University Press, 1998.

PUGH K., \& M. GIROD, (2007), "Science, Art, and Experience: Constructing a Science Pedagogy from Dewey's Aesthetics," Journal of Science Teacher Education, 18, 9-27.

SHORT T., (2007), Peirce's Theory of Signs, New York, Cambridge University Press.

WAKS L., (1981), “Experimentalism and the Flow of Experience," Educational Theory, 1 (47), 1-19.

\section{NOTES}

1. Doug Anderson has given an extensive analysis of creativity and the work of Peirce. However, I disagree with the distinction between the "final looks" of artistic creativity and scientific discovery (Anderson 1987: 54). In this particular paper, the argument is not one directly aimed at this distinction, and is thus here outside the scope of my analysis. In addition, I agree with both Max Hocutt 1962 and C.M. Smith 1972 that Peirce, as he admitted, never adequately developed an aesthetics. Dewey provides a much better conception of aesthetic experience with which to work, especially with regard to scientific explanation.

2. I take issue with Godfrey-Smith's use of the term 'disinterested' here. Although Dewey claims that most scientific practice consists in secondary experience with regard to analyzing and synthesizing what has occurred within primary experience, I think he would find it difficult to accept that scientists would bother to inquire into experience if they were disinterested in that experience.

3. Here Peirce provides what I believe is sorely lacking in Dewey, categorical divisions by which to understand experience. Although Dewey's conceptions of primary and secondary experience are useful, especially with regard to broad types of experience (emotive, intellectual, aesthetic), Peirce's categories are much more useful for understanding the relationships within those experiences. Here I only briefly touch upon how these categories relate to the creative moment of scientific apprehension, acknowledging that further work on this particular aspect of the phenomenon would prove beneficial to our understanding.

\section{ABSTRACTS}

Scientific explanation is both instrumental and consummatory. When we experience scientific explanation in its consummation, we experience what I have deemed a creative moment of scientific apprehension, which is an important aspect of creativity that comes at the end of inquiry and contributes to the development of future inquiry. Because scientific explanation is commonly cleaved from aesthetic experience, this moment of creativity has been neglected in both analyses of scientific practice and analyses of aesthetic experience. By synthesizing John Dewey's conceptions of scientific explanation and aesthetic experience with Charles S. Peirce's categories, this moment of scientific inquiry is revealed and understood as a fundamental part of our 
creative reasoning process. In order to argue that scientific explanation is both instrumental and consummatory, Dewey's instrumental conception of scientific explanation is provided, which includes why science is so often considered as separated from aesthetic experience. A general overview of Dewey's conception of aesthetic experience and the common division conceived between scientific experience and that of aesthetics is also provided. Reasons are then supplied to reconsider scientific experience as having an aesthetic dimension, especially with regard to scientific explanations and the creative moment of scientific apprehension, which is followed by a brief discussion concerning how recognition of this moment reveals an important aspect of creative reasoning that is to be understood as a part of our experience through what Peirce referred to as firstness and secondness. Analyzing the aesthetic experience of scientific explanations against the backdrop of Dewey's conceptions of aesthetics and science, combined with Peirce's categories, accounts for that creative moment of scientific apprehension in which a scientific explanation takes on the quality of kalos, or sense of general harmony, that inspires reverie and future inquiry.

\section{AUTHOR}

\section{MARK DIETRICH TSCHAEPE}

Prairie View A\&M University

mdtschaepe[at]pvamu.edu 